\title{
Correlation of the Rates of Solvolyses of Carbomethoxybenzyl Bromides Using the Grunwald-Winstein Equation
}

\author{
Jin Burm Kyong, ${ }^{*}$ Hoshik Won, Young Hoon Lee, ${ }^{\dagger}$ and Dennis N. Kevill ${ }^{\ddagger}$ \\ Department of Chemistry, Hanyang University, Ansan, Kyunggi 425-791, Korea. *E-mail: jbkyong@hanyang.ac.kr \\ ${ }^{\dagger}$ Department of Chemistry, Hanseo University, Seosan 325-820, Korea \\ ${ }^{\ddagger}$ Department of Chemistry and Biochemistry, Northern Illinois University, Dekalb, Illinois 60115-2862, U.S.A.
}

Received August 30, 2004

Key Words : Carbomethoxybenzyl bromide, Grunwald-Winstein equation

Some years ago, Andrews and co-workers ${ }^{1,2}$ studied the effects of ortho-substitution on nucleophilic substitution reactions of benzylic derivatives in $80 \%$ aqueous dioxane. They proposed that ortho-groups possessing a nucleophilic center could give intramolecular assistance to reactions; the relatively high reactivity of the ortho isomer has been explained on the assumption that its carboxylic acid group can participate electronically in the activation process by releasing electrons to the vacant $p$-orbital developing at the reaction center. Although previous workers have carried out some product studies showing intramolecular participation, they show only a profile of the products after completion of reaction. As mentioned above, the solvolyses of orthosubstituted benzyl halides have been less studied kinetically.

The extended Grunwald-Winstein equation [eqn.(1)] has been applied to a powerful mechanistic tool for solvolysis reactions. $^{3}$

$$
\log (k / k o)=l \mathrm{~N}_{T}+m \mathrm{Y}_{X}+\mathrm{c}
$$

In eqn. (1), $k$ and $k_{o}$ are the specific rates of solvolysis in a given solvent and in the standard solvent (80\% ethanol), respectively; $l$ is the sensitivity towards changes in solvent nucleophilicity $\left(N_{T}\right) ;{ }^{4} m$ is the sensitivity towards changes in solvent ionizing power $\left(Y_{X}\right) ;^{5,6} \mathrm{c}$ is a residual term. The equation is a very useful indicator of the extent of nucleophilic participation by the solvent, as expressed in the parameter, $l$, which, in turn, is directly related to whether a substitution reaction is unimolecular or bimolecular pathway. In general, for an ionization reaction without nucleophilic assistance, $l$ will be zero and $m$ close to unity, and, for a reaction proceeding with extensive nucleophilic assistance, the $l$ value will be in the region of 0.7 to 1.7 and the $m$ value in the region of 0.3 to 0.5 . Accordingly, determination of these values will be a valuable source of information concerning the structure of the transition state for these solvolyses.

In the present paper, we analyze the specific rates of solvolyses of the ortho (1) and para (2) carbomethoxybenzyl bromides in terms of both simple [eqn. (1) without the $l \mathrm{~N}_{\mathrm{T}}$ term] and extended Grunwald-Winstein equation, and we compare the $l$ and $\mathrm{m}$ values obtained for the $o$ - isomer (1) with those obtained in the solvolysis of the $p$-isomer (2) in a wide variety of solvents, in order to investigate the effect of intermolecular or intramolecular assistance by the orthosubstituent (eqn. 2).

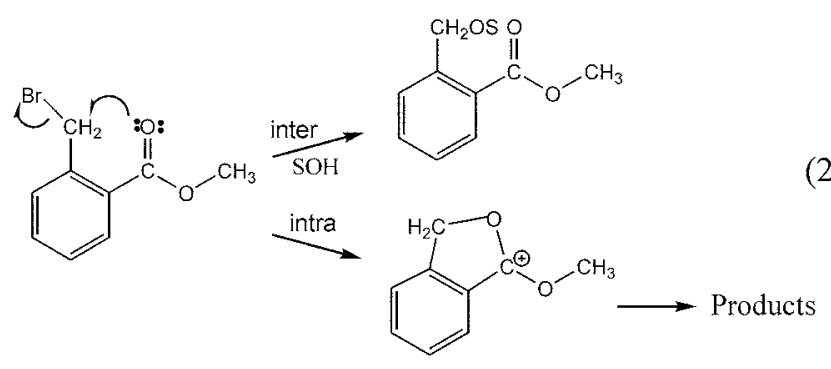

Results and Discussion

The specific rates of solvolyses for $o$-isomer (1) and $p$ isomer (2) were determined in 19 solvents at $45.1{ }^{\circ} \mathrm{C}$. The solvents consisted of ethanol, methanol, binary mixtures of water with ethanol, methanol, 2,2,2-trifluoroethanol (TFE) and acetone, and four binary mixtures of TFE and ethanol. The specific rates of solvolyses for these two substituted benzyl bromides are reported in Table 1, together with the available $\mathrm{N}_{T}$ and $\mathrm{Y}_{B r}$ values. Also, in Table 1 are presented the ratios $\left(k_{\text {ortho }} / k_{\text {para }}\right)$ of the specific rates for solvolyses of $o$ isomer (1) and $p$-isomer (2).

For $80 \% \mathrm{EtOH}$ and $97 \% \mathrm{TFE}$, runs were also carried out at three additional temperatures for $o$-isomer (1), and these data are reported in the footnotes to Table 1. These values, together with those for these solvents at $45.1{ }^{\circ} \mathrm{C}$, were used to obtain the enthalpies and entropies of activation reported in the footnotes to Table 1.

Solvolyses of ortho and para carbomethoxybenzyl bromides. In general the reactivities of $o$-substituted benzyl halide solvolyze more slowly than their $p$-isomers. The comparatively low reactivities of the $o$-isomers may result because of steric hindrance by the ring substituents to solvation of the exocyclic carbon atom in the transition state. However, as shown in Table 1, the $k_{o b s}$ for reaction of the $o$ isomer (1) in all the solvents is solvolyzed more rapidly than its $p$-isomer (2), but the differences in reactivity are not so great as those observed for the carboxybenzyl bromides $\left(k_{o} / k_{p} \cong 80\right.$ in $80 \%$ dioxane $) .{ }^{1}$ It is, therefore, concluded that ring substituent of the $o$-carbomethoxy group dose not function very effectively as a participant in the reaction. 
Table 1. Specific rate constants for the solvolyses of ortho $(\mathbf{1})^{a}$ and para $(\mathbf{2})^{b}$ carbomethoxybenzyl bromides in several solvents at 45.1 ${ }^{\circ} \mathrm{C}$

\begin{tabular}{lllrrr}
\hline \multicolumn{1}{c}{ solvent $^{c}$} & \multicolumn{1}{c}{$\begin{array}{c}10^{5} k_{\text {ortho, }} \\
\left(\mathrm{sec}^{-1}\right)\end{array}$} & \multicolumn{1}{c}{$\begin{array}{c}10^{5} k_{\text {para, }} \\
\left(\mathrm{sec}^{-1}\right)\end{array}$} & $\mathrm{N}_{\mathrm{T}}{ }^{d}$ & $\mathrm{Y}_{\mathrm{Br}}{ }^{e}$ & $\begin{array}{c}k_{\text {ortho }} / \\
k_{\text {para }}\end{array}$ \\
\hline $100 \mathrm{EtOH}{ }^{f}$ & $0.286 \pm 0.01$ & $0.142 \pm 0.01$ & 0.37 & -2.40 & 2.01 \\
$90 \mathrm{EtOH}$ & $0.688 \pm 0.003$ & $0.393 \pm 0.006$ & 0.16 & -0.84 & 1.75 \\
$80 \mathrm{EtOH}$ & $1.17^{h} \pm 0.01$ & $0.640 \pm 0.005$ & 0.00 & 0.00 & 1.83 \\
$70 \mathrm{EtOH}$ & $1.72 \pm 0.008$ & $0.953 \pm 0.03$ & -0.20 & 0.68 & 1.80 \\
$50 \mathrm{EtOH}$ & $3.69 \pm 0.09$ & $1.97 \pm 0.04$ & -0.58 & 1.88 & 1.88 \\
$100 \mathrm{MeOH}$ & $0.943 \pm 0.02$ & $0.391 \pm 0.05$ & 0.17 & -1.12 & 2.41 \\
$90 \mathrm{MeOH}$ & $1.89 \pm 0.02$ & $0.754 \pm 0.01$ & -0.01 & -0.14 & 2.51 \\
$80 \mathrm{MeOH}$ & $2.96 \pm 0.05$ & $1.34 \pm 0.02$ & -0.06 & 0.70 & 2.21 \\
$60 \mathrm{MeOH}$ & $6.67 \pm 0.08$ & $3.19 \pm 0.03$ & -0.54 & 2.04 & 2.09 \\
$50 \mathrm{MeOH}$ & $9.74 \pm 0.04$ & $4.49 \pm 0.08$ & -0.75 & 2.61 & 2.17 \\
$80 \mathrm{Me}{ }_{2} \mathrm{CO}$ & $0.264 \pm 0.01$ & $0.127 \pm 0.005$ & -0.37 & -0.70 & 2.07 \\
$60 \mathrm{Me}{ }_{2} \mathrm{CO}$ & $1.03 \pm 0.02$ & $0.507 \pm 0.01$ & -0.52 & 1.03 & 2.02 \\
$50 \mathrm{Me}{ }_{2} \mathrm{CO}$ & $1.60 \pm 0.01$ & $0.890 \pm 0.02$ & -0.70 & 1.74 & 1.80 \\
$97 \mathrm{TFE}{ }^{i}$ & $1.23 \pm 0.01^{j}$ & - & -3.3 & 2.53 & - \\
$90 \mathrm{TFE}$ & $1.42 \pm 0.02$ & $0.0206 \pm 0.004$ & -2.55 & 2.60 & 68.9 \\
$70 \mathrm{TFE}$ & $1.98 \pm 0.04$ & $0.195 \pm 0.02$ & -1.98 & 2.79 & 10.2 \\
$50 \mathrm{TFE}{ }^{g}$ & $2.93 \pm 0.05$ & $0.603 \pm 0.01$ & -1.73 & 3.04 & 4.86 \\
$60 \mathrm{~T}-40 \mathrm{E}^{k}$ & $0.532 \pm 0.006$ & $0.0743 \pm 0.002$ & -1.76 & 1.62 & 7.16 \\
$40 \mathrm{~T}-60 \mathrm{E}$ & $0.445 \pm 0.005$ & $0.113 \pm 0.02$ & -0.94 & 0.31 & 3.94 \\
$20 \mathrm{~T}-80 \mathrm{E}$ & $0.390 \pm 0.005$ & $0.125 \pm 0.02$ & 0.08 & -1.42 & 3.12 \\
\hline
\end{tabular}

${ }^{a}$ Substrate concentration of $c a .4 .392 \times 10^{-3} \mathrm{M} .{ }^{b}$ Substrate concentration of $\mathrm{ca} .3 .204 \times 10^{-3} \mathrm{M}$. ${ }^{c}$ Volume/volume basis at $25.0^{\circ} \mathrm{C}$, except for TFE$\mathrm{H}_{2} \mathrm{O}$ mixtures, which are on a weight/weight basis. ${ }^{d}$ Based on the specific rates of solvolysis of the $\mathrm{S}$-methyldibenzothiophenium ion, from ref. 3 and ref. $4 .{ }^{e} \mathrm{Y}_{\mathrm{Br}}$ values of 1 -adamantyl bromide from ref. 5 and ref. 6. 'Percentage of products for the solvolysis of these substrates: $o$-isomer, $100 \% \mathrm{EtOH} ; o$-carbomethoxybenzyl ethyl ether(retention time: $12.60 \mathrm{~min}$. $89.24 \%$ ), phthalide(retention time: $39.06 \mathrm{~min} .10 .76 \%$ ), ${ }^{f 50} \% \mathrm{EtOH}$; $o$ carbomethoxybenzyl ethyl ether (retention time: $12.60 \mathrm{~min} .56 .53 \%$ ), phthalide (retention time: $39.06 \mathrm{~min} .43 .47 \%$ ), $p$-isomer, $50 \% \mathrm{EtOH}, p$ carbomethoxybenzyl ethyl ether (retention time: $9.49 \mathrm{~min} .63 .83 \%$ ), $p$ carbomethoxybenzyl alcohol (retention time: $58.42 \mathrm{~min} .36 .17 \%$ ). ${ }^{g} \mathrm{O}^{-}$ isomer, 50\% TFE; $o$-carbomethoxybenzyl trifluoroethyl ether (retention time: $9.72 \mathrm{~min} .1 .58 \%$ ), phthalide (retention time: $39.06 \mathrm{~min} .98 .42 \%$ ) ${ }^{h} \mathrm{At}$ $35.1{ }^{\circ} \mathrm{C}, 58.1{ }^{\circ} \mathrm{C}$, and $62.5^{\circ} \mathrm{C}$, values of $(0.389 \pm 0.002) \times 10^{-5} \mathrm{sec}^{-1}$, $(3.98 \pm 0.03) \times 10^{-5} \mathrm{sec}^{-1}$, and $(6.22 \pm 0.07) \times 10^{-5} \mathrm{sec}^{-1}$, respectively, were obtained. $\Delta \mathrm{H}^{\neq}=20.1 \mathrm{kcal} \cdot \mathrm{mol}^{-1}$ and $\Delta \mathrm{S}^{\neq}=-18.4 \mathrm{cal} \cdot \mathrm{K}^{-1} \cdot \mathrm{mol}^{-1}$ ${ }^{i}$ TFE is 2,2,2-trifluoroethanol. ${ }^{j}$ At $35.1^{\circ} \mathrm{C}, 58.1{ }^{\circ} \mathrm{C}$, and $62.5^{\circ} \mathrm{C}$, values of $(0.386 \pm 0.006) \times 10^{-5} \mathrm{sec}^{-1},(4.98 \pm 0.07) \times 10^{-5} \mathrm{sec}^{-1}$, and $(7.35 \pm$ $0.07) \times 10^{-5} \mathrm{sec}^{-1}$, respectively, were obtained. $\Delta \mathrm{H}^{\neq}=21.6 \mathrm{kcal} \cdot \mathrm{mol}^{-1}$ and $\Delta \mathrm{S}^{\neq}=-13.3 \mathrm{cal} \cdot \mathrm{K}^{-1} \cdot \mathrm{mol}^{-1}$. (cf. ref. $1 ; 80 \%$ dioxane, $\Delta \mathrm{H}^{\neq}=20.8$ $\mathrm{kcal} \cdot \mathrm{mol}^{-1}$ and $\left.\Delta \mathrm{S}^{\neq}=-19.7 \mathrm{cal} \cdot \mathrm{K}^{-1} \cdot \mathrm{mol}^{-1}\right) .{ }^{k}$ T-E is 2,2,2-trifluoroethanol and ethanol.

Andrews and co-workers ${ }^{1}$ have demonstrated that the high reactivity of the $o$-carboxybenzyl bromide is rationalized in terms of internal participation by a neighboring carboxy group.

The ratios, $k_{50 \mathrm{MeOH}} / k_{90 \mathrm{TFE}}$, of solvolysis rates for $o$-isomer (1) and $p$-isomer (2) in the solvent of different nuleophilicity but the similar ionizing power were 7 and 218, respectively. The smaller ratio for $o$-isomer (1) indicates appreciably less sensitivity to nucleophilic attack.

A consideration in terms of the simple Grunwald-Winstein equation [eqn. (1) without the $l \mathrm{~N}_{\mathrm{T}}$ term] to the specific rates of solvolysis of $p$-isomer (2) leads to a poor correlation with value of 0.3235 for the correlation coefficient (r). Again,

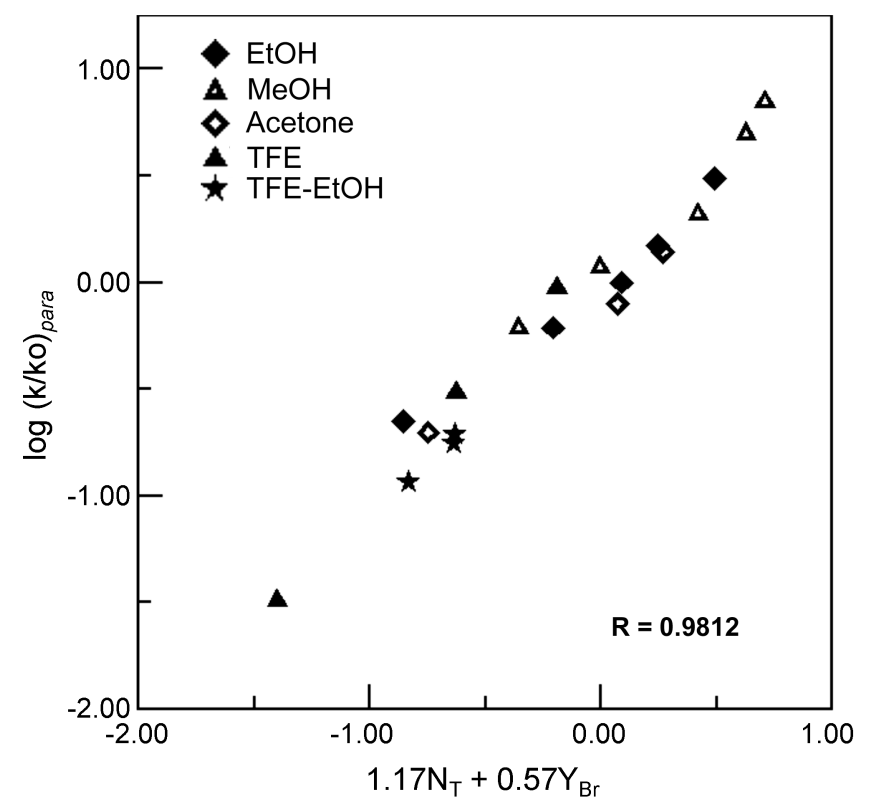

Figure 1. Plot of $\log \left(k / k_{0}\right)_{\text {para }}$ vs. $1.17 \mathrm{~N}_{\mathrm{T}}+0.57 \mathrm{Y}_{\mathrm{Br}}$ for $p$-carbomethoxybenzyl bromide in several solvents at $45.1{ }^{\circ} \mathrm{C}$.

analysis of the data using the extended Grunwald-Winstein equation [eqn. (1)] leads to an excellent linear correlation with values of 1.17 for $l, 0.57$ for $m, 0.10$ for $c$, and 0.9812 for the correlation coefficient (Figure 1). These $l$ and $m$ values are similar to those obtained to reflect the bimolecular pathway within the analyses of the solvolyses of $p$-nitrobenzyl $p$-toluenesulfonates, ${ }^{7}$ and $p$-carboxybenzyl bromide. ${ }^{8}$

Also an analysis in terms of the simple GrunwaldWinstein equation to solvolysis of $o$-isomer (1) gives value of 0.7849 for the correlation coefficient. Using the full equation (1), the correlation is considerably improved, although still rather unsatisfactory, with values of 0.53 for $l$, 0.41 for $m, 0.06$ for $c$, and 0.932 for the correlation coefficient. To study the nucleophilic solvent participation in benzylic solvolysis, we applied the use of a new term, aromatic ring parameter $I .{ }^{8}$ Correlation values for all of the data (13 solvents), except aqueous fluoroalcohols and fluoroalcohol-ethanol mixtures are obtained of 0.65 for $l$, 0.47 for $m, 1.38$ for $I, 0.05$ for $c$, and 0.953 for the correlation coefficient. A rather low correlation value suggests that, as with $o$-carboxybenzyl bromide, there is due to the operation of two reaction mechanisms, which we believe involve nucleophilic attack by solvent (paralleling the mechanism for para carbomethoxybenzyl bromide solvolysis) and intramolecular attack by the $o$-carbomethoxy group, as previously proposed. ${ }^{8}$

The values of the entropy of activation with $o$-isomer (1) in $80 \% \mathrm{EtOH}$ and $80 \%$ dioxane are more negative than those in $97 \%$ TFE. It is obvious that the different values between the solvolysis of $o$-isomer in the fluoroalcohols and those in nucleophilic solvents probably proceeds via different reactivity.

Analysis of the rate coefficients of aqueous TFE and TFEEtOH Data points. As can be seen in Figure 2, for solvents of relatively high nucleophilicity and low ionizing power 


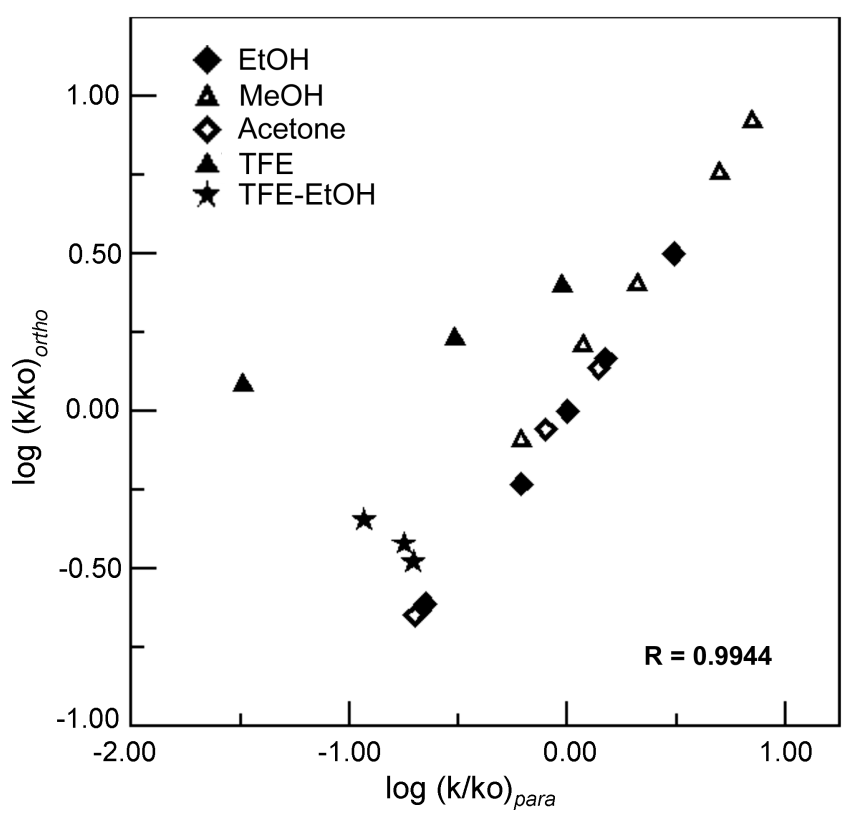

Figure 2. Plot of $\log \left(k / k_{0}\right)_{\text {ortho }} v s$. $\log \left(k / k_{0}\right)_{\text {para }}$ for ortho and para carbomethoxybenzyl bromides in several solvents at $45.1{ }^{\circ} \mathrm{C}$.

(excluding aqueous fluoroalcohols and fluoroalcoholethanol mixtures), a good linear correlation of $\log \left(k / k_{o}\right)$ for the reaction of $o$-isomer (1) and $p$-isomer (2) is observed, with a slope of 1.00, intercept of 0.046 and an excellent correlation coefficient of 0.9944 [eqn. (3)].

$$
\begin{gathered}
\log \left(k_{\text {solv. }} / k_{o}\right)_{\text {ortho }}=1.004 \log \left(k_{\text {solv. }} / k_{o}\right)_{\text {para }}+0.04567 \\
k_{\text {intra }}=k_{\text {ortho }}-k_{\text {solv. }}
\end{gathered}
$$

When the points for the fluoroalcohols are taken into consideration they lie considerably above the plot, especially for the solvents containing aquous TFE, with the deviations being a measure of the importance of the intramolecular pathway. In this way, the overall rate coefficients can be subdivided into the two components, which can each be analyzed separately using eqn. (1). In Table 2 are presented the rate coefficients for solvolysis of the nucleophilic attack by solvent $\left(k_{\text {solv }}\right)$ and intramolecular attack by the $o$ carbomethoxy group $\left(k_{\text {intra }}\right)$ in aqueous TFE and TFE-EtOH

Table 2. The rate coefficients for solvolysis of the nucleophilic attack by solvent $\left(k_{s o l v}\right)$ and intramolecular attack by the ortho carbomethoxy group $\left(k_{\text {intra }}\right)$ in aqueous TFE and TFE-EtOH mixtures at

\begin{tabular}{|c|c|c|c|}
\hline solvent & $10^{5} k_{\text {ortho }},\left(\mathrm{sec}^{-1}\right)$ & $10^{5} k_{\text {solv }}^{c},\left(\mathrm{sec}^{-1}\right)$ & $10^{5} k_{\text {intra, }}^{d}\left(\mathrm{sec}^{-1}\right)$ \\
\hline 90TFE ${ }^{a}$ & 1.42 & 0.0411 & 1.38 \\
\hline 70TFE & 1.98 & 0.392 & 1.59 \\
\hline 50TFE & 2.93 & 1.23 & 1.71 \\
\hline $60 \mathrm{~T}-40 \mathrm{E}^{b}$ & 0.532 & 0.149 & 0.383 \\
\hline 40T-60E & 0.445 & 0.227 & 0.218 \\
\hline $20 \mathrm{~T}-80 \mathrm{E}$ & 0.390 & 0.251 & 0.139 \\
\hline
\end{tabular}
$45.1^{\circ} \mathrm{C}$

${ }^{a} 2,2,2$-Trifluoroethanol-water (w/w\%). ${ }^{b} 2,2,2$-Trifluoroethanol-Ethanol $(\mathrm{v} / \mathrm{v} \%) .{ }^{c}$ Calculated from $\log \left(k_{\text {solv }} / k_{o}\right)_{\text {ortho }}=1.004 \log \left(k_{\text {solv }} / k_{o}\right)_{\text {para }}+$ 0.04567. ${ }^{d}$ Calculated from $k_{\text {intra }}=k_{\text {ortho }}-k_{\text {solv }}$.
Table 3. Correlation of rate constants for the solvolyses of para and ortho substituented benzyl bromides using the extended GrunwaldWinstein equation

\begin{tabular}{ccccccc}
\hline Substrate & $\mathrm{n}^{a}$ & $l^{b}$ & $m^{b}$ & $1 / m$ & $\mathrm{c}^{b}$ & $\mathrm{r}^{c}$ \\
\hline$p-\mathrm{CBB}^{d}$ & 15 & 1.24 & 0.59 & 2.10 & 0.10 & 0.973 \\
$o-\mathrm{CBB}^{e}$ & 12 & 0.73 & 0.41 & 1.78 & 0.01 & 0.952 \\
$p-\mathrm{CMB}^{f}$ & 19 & 1.17 & 0.57 & 2.05 & 0.09 & 0.981 \\
$o-\mathrm{CMB}^{g}$ & 19 & 0.53 & 0.41 & 1.29 & 0.06 & 0.932 \\
$o-\mathrm{CMB}^{g}$ & 13 & 0.65 & 0.47 & 1.38 & 0.05 & 0.953 \\
$o-\mathrm{CMB}^{g}$ & 6 & $\sim 0$ & 0.24 & - & -0.58 & 0.999 \\
\hline
\end{tabular}

${ }^{a}$ Number of solvent systems included in the correlation. ${ }^{b}$ Using eq. 1 ${ }^{c}$ Correlation coefficient. ${ }^{d} p$-carboxybenzyl bromide, ref. $8 .{ }^{e} o$-carboxybenzyl bromide, ref. 8. ${ }^{f} p$-carbomethoxybenzyl bromide. ${ }^{g} O$-carbomethoxybenzyl bromide.

mixtures. For the $k_{\text {intra }}$ in Table 2 , the m value $(m \cong 0.24)$ for $o$-isomer (1) suggests an early transition state for these reactions with intramolecular nucleophilic assistance. ${ }^{9}$ In Table 3, a large negative c-value of $o$-isomer (1) in aqueous fluoroalcohols and fluoroalcohol-ethanol mixtures is observed because the experimental $k_{o}$ value is the one applying to the other reaction channel.

In conclusion, we found that the specific rates of solvolyses of $p$-isomer (2) and $o$-isomer (1) lead to an exellent correlation $(\mathrm{r}=0.981)$ and a rather low correlation $(\mathrm{r}=$ 0.953) from analysis of the data using the extended Grunwald-Winstein equation [eqn. (1)] and a new term, aromatic ring parameter $I$., respectively. The solvolysis of $p$ isomer $(2)$, where bond making $(l=1.17)$ is more progressed than bond breaking $(m=0.57)$, is indicated to proceed by a bimolecular pathway, reflecting nucleophilic assistance from a solvent molecule. And it is shown that the solvolysis of $o$ isomer (1) in all the solvents can be affected not only by nucleophilic assistance paralleling the mechanism for $p$ isomer (2) but also by intramolecular assistance of the $O$ carbomethoxy group.

\section{Experimental Section}

$o$-Carbomethoxybenzyl bromide $\left(o-\mathrm{BrCH}_{2} \mathrm{C}_{6} \mathrm{H}_{4} \mathrm{CO}_{2} \mathrm{CH}_{3}\right)$ was prepared from the correspoding methyl-2-methylbenzoate (Aldrich, $\mathrm{CH}_{3} \mathrm{C}_{6} \mathrm{H}_{4} \mathrm{CO}_{2} \mathrm{CH}_{3}$ ) according to previously published procedures, ${ }^{10} \mathrm{mp}$. 30-32 ${ }^{\circ} \mathrm{C}$ (lit. ${ }^{1} 32-32.5{ }^{\circ} \mathrm{C}$ ). $p$ Carbomethoxybenzyl bromide (Aldrich, $p$ - $\mathrm{BrCH}_{2} \mathrm{C}_{6} \mathrm{H}_{4} \mathrm{CO}_{2-}$ $\mathrm{CH}_{3}$ ) was recrystallized from ligroin, mp. 55-56 ${ }^{\circ} \mathrm{C}$ (lit. ${ }^{1} 54-$ $55^{\circ} \mathrm{C}$ ). Solvents were purified and the kinetic runs carried out as previously described. ${ }^{11,12}$ All runs were performed at least in duplicate. The $l, m$ and $I$ values were calculated using the multiple regression analyses. The products from the reactions of $o$-isomer (1) and $p$-isomer (2) under solvolytic conditions were analyzed after 10 half-lives by gas chromatography (GC-9A) and gas chromatography/ mass spectroscopy (Agilent 6890N GC/5973N MSD) as previously described. ${ }^{11}$

Acknowledgment. This work was supported by the research fund of Hanyang University (HY-2003-T). 


\section{References}

1. Singh, A.; Andrews, L. J.; Keefer, R. M. J. Am. Chem. Soc. 1962, 84, 1179.

2. Strauss, M. J.; Harman, I.; Andrews, L. J.; Keefer, R. M. J. Am. Chem. Soc. 1968, 90, 3473.

3. Kevill, D. N. In Advances in Quantitative Structure-Property Relationships; Charton, M., Ed.; Jai Press: Greenwich, CT, 1996; Vol. I, pp 81-115.

4. Kevill, D. N.; Anderson, S. W. J. Org. Chem. 1991, 56, 1845.

5. Bentley, T. W.; Llewellyn, G. Prog. Phys. Org. Chem. 1990, 17, 121.
6. Bentley, T. W.; Carter, G. E. J. Am. Chem. Soc. 1982, 104, 5741.

7. Kevill, D. N.; D'Souza, M. J.; Ren, H. Can. J. Chem. 1998, 76, 751.

8. Ra, J. W.; Kyong, J. B.; Kevill, D. N. Bull. Korean Chem. Soc. 2002, 23, 1680.

9. Streltwieser, A. In Solvolytic Displacement Reactions; McGrawHill: New York, 1962; p 2538.

10. Eliel, E. L.; Rivard, D. E. J. Org. Chem. 1952, 17, 1252.

11. Kyong, J. B.; Park, B. C.; Kim, C. B.; Kevill, D. N. J. Org. Chem. 2000, 65, 8051.

12. Park, J. K.; Myoung, J. J.; Kyong, J. B.; Kim, H. K. Bull. Korean Chem. Soc. 2003, 24, 671. 